\section{Study of possible risk factors for severe retinopathy in non-insulin dependent diabetes}

Diabetic retinopathy is one of the commonest causes of visual loss in Britain. ${ }^{1}$ Various factors have been reported to be associated with retinopathy, but few studies have looked at these in relation to aetiological type of diabetes or severity of complications. We report a study of possible risk factors for severe retinopathy in a group of non-insulin dependent diabetics selected from our clinic.

\section{Patients, methods, and results}

We selected consecutively from the clinic 100 non-insulin dependent diabetics. Fifty had severe retinopathy (proliferative retinopathy or maculopathy) that had developed within 10 years of diagnosis (group 1), and 50 had no evidence of microvascular complications after more than 14 years of diabetes (group 2). Non-insulin dependent diabetes was diagnosed if patients developed diabetes'in middle or late life without ketosis. Groups were compared with respect to sex, cigarette smoking, blood pressure, serum creatinine concentration, family history, treatment regimens, and glycaemic control. Blood pressure was measured by the same observer after three minutes' recumbency. Diastolic pressure was recorded as fifth phase (fourth phase if no clear end point). Glycaemic control was assessed as mean laboratory blood glucose value over the previous five years, most subjects having had a mid-morning and afternoon measurement before each clinic visit. Results were analysed by a Wilcoxon $\mathrm{U}$ or $\%^{2}$ test.

Mean clinic blood glucose values and current treatment regimens in groups 1 and $2^{*}$

\begin{tabular}{lcc}
\hline & Group 1 & Group 2 \\
\hline Mean (SEM) blood glucose $(\mathrm{mmol} / 1)$ & $8 \cdot 8(0 \cdot 4)$ & $8 \cdot 9(0 \cdot 3)$ \\
Treatment required: & 3 & 4 \\
Diet alone & 25 & 18 \\
Sulphonylurea $\left\{\begin{array}{l}\text { Half of maximum dose } \\
\text { Half of maximum dose }\end{array}\right.$ & 13 & 21 \\
Insulin & 9 & 7
\end{tabular}

*There were no significant differences in mean clinic blood glucose measurements over previous five years or in current treatment regimens.

Conversion: SI to traditional units-Glucose: $1 \mathrm{mmol} / 1 \approx 18 \mathrm{mg} / 100 \mathrm{ml}$.

There were no significant differences in mean age (63 SEM 1) $v 62(0.9)$ years) or percentage of ideal body weight (124 (SEM 4) $v 120(5)$ ) between groups 1 and 2. Duration of diabetes was longer in group 2 (18 (SEM 0.7) years, range $15-34, v 10(0.8)$ years, range $1-22)$. Mean blood pressure was significantly greater in group 1 than in group 2 (systolic 172 (SEM 5) $v 142$ (3) $\mathrm{mm} \mathrm{Hg}$, and diastolic 93 (2) $v 80(2) \mathrm{mm} \mathrm{Hg} ; \mathrm{p}<0.001$ ). Twenty two subjects in group 1 and two in group 2 were receiving antihypertensive agents $(\mathrm{p}<0.001)$. In group 1 six subjects had persistent proteinuria of whom five had a raised serum creatinine concentration (range 130-200 $\mu \mathrm{mol} / 1$; $1.5-$ $2.3 \mathrm{mg} / 100 \mathrm{ml}$ ). There were significantly more women in group 1 than in group $2(31 / 50 v 21 / 50 ; \mathrm{p}<0.05)$. There were no significant differences in frequency of first degree family history of diabetes (20 in group $1 v 25$ in group 2) or cigarette smoking (eight current and four previous smokers in past five years in group $1 ; 11$ and 5 respectively in group 2). Mean clinic blood glucose concentrations over the previous five years were similar, as were the treatment regimens (table). Eleven subjects in group 1 and six in group 2 had coincident coronary artery, cerebrovascular, or peripheral vascular disease.

\section{Comment}

In this study hypertension, and to a less extent female sex, was most strongly associated with severe retinopathy in non-insulin dependent diabetes. No significant associations were found with cigarette smoking, family history, body weight, or diabetic control. An association between hypertension and retinopathy has been reported in insulin dependent diabetics ${ }^{2}$ and Pima Indians, ${ }^{3}$ but other reports have not separated patients into aetiological types or according to severity of complications. ${ }^{14}$ It has been suggested that the association might be related to coincident renal disease, but in our study only five subjects had renal impairment. An excess of female patients with retinopathy has been reported ${ }^{5}$ and may simply reflect the greater frequency of non-insulin dependent diabetes in women, but this would not explain why men predominated in our uncomplicated group. Surprisingly, glycaemic control and treatment regimens were similar in the two groups, but this may reflect our imperfect assessment of glycaemic control. Possibly poor control before complications develop is more important in the pathogenesis of microangiopathy.

We conclude that of the possible risk factors examined in patients with non-insulin dependent diabetes, hypertension was most closely associated with severe retinopathy.

' Keen $\mathrm{H}$. Prevalence of blindness in diabetics. $\mathcal{f} R$ Coll Physicians Lond 1972; 7:53-60.

${ }^{2}$ Bodansky HJ, Cudworth AG, Drury PL, Kohner EM. Risk factors associated with severe proliferative retinopathy in insulin-dependent diabetes mellitus. Diabetes Care 1982;5:97-100.

${ }^{3}$ Knowler WC, Bennett PH, Ballintine EJ. Increased incidence of retinopathy in diabetics with elevated blood pressure. $N$ Engl 7 Med 1980; 302:645-50.

4 Job D, Tchobroutsky G, Eschwege E, et al. Relationship between diabetic retinopathy, blood pressure, body weight and serum lipid levels. Diabetologia 1973;9:74.

${ }^{5}$ Tsuji S, Wada M, eds. Diabetes mellitus in Asia 1970. Amsterdam: Excerpta Medica, 1971.

(Accepted 26 April 1983)

Department of Medicine, Royal South Hants Hospital, Southampton SO9 4PE

ANTHONY H BARNETT, MD, MRCP, senior registrar

JOHN R BRITTON, MRCP, registrar

BRIAN A LEATHERDALE, MRCP, consultant physician

Correspondence to: Dr Anthony $\mathrm{H}$ Barnett, senior lecturer, Department of Medicine, East Birmingham Hospital, Bordesley Green East, Birmingham B9 5ST.

\section{Pneumococcal bacteraemia in mother and son}

Epidemics of pneumococcal infection have been described in certain crowded communities ${ }^{12}$ but in most British homes the risk of catching pneumococcal pneumonia from an affected relative is generally regarded as small. ${ }^{3}$ No special precautions are taken against cross infection, although the mortality from pneumococcal pneumonia (especially when accompanied by bacteraemia) is high. ${ }^{4}$ We describe the case of a mother with pneumonia and bacteraemia caused by Streptococcus pneumoniae type 1 who transmitted the disease to her son. The mother was admitted to hospital first and the son, though ill, did not seek medical attention.

\section{Case histories}

Case 1-A 69 year old woman with chronic bronchitis was admitted to this hospital with a two day history of increasing dyspnoea, left sided pleuritic pain, and non-productive cough. She was confused, tachypnoeic, feverish $\left(38^{\circ} \mathrm{C}\right)$, centrally cyanosed, and had signs of pulmonary consolidation at the left base. A chest radiograph confirmed collapse of the lower lobe and consolidation. Blood was obtained for culture but no sputum could be produced. Treatment was instituted with $500 \mathrm{mg}$ ampicillin and $500 \mathrm{mg}$ cloxacillin intravenously four times a day and general supportive measures. $S$ pneumoniae capsular type 1 was isolated from the blood culture after overnight incubation. Treatment was changed to benzylpenicillin $2 \mathrm{mU}$ six hourly. She had a very stormy course requiring monitored low dose oxygen for hypoxia, hypercapnia, and transient collapse of the whole left lung and was discharged on the 18th day. Two days after admission relatives had sought advice about her son, who lived in the same two bedroomed house. He had similar symptoms but did not wish to see a doctor. The general practitioner was alerted and on visiting confirmed that the son required urgent admission to hospital.

Case 2-The 32 year old son presented with a history of severe dyspnoea and pleuritic chest pain on the right. Since his mother's admission four days 
previously he had felt generally unwell and had experienced rigors the day before admission. He had a history of asthma but was not taking regular medication and had never been given corticosteroids. He was feverish $\left(38^{\circ} \cdot 6^{\circ} \mathrm{C}\right)$ and the radiograph showed a dense area of consolidation in the right upper lobe. Sputum and blood were obtained for culture and treatment begun with benzylpenicillin. The fever resolved within 24 hours of starting treatment and he recovered uneventfully. $S$ pneumoniae capsular type 1 was isolated from the blood culture after overnight incubation. Sputum culture yielded mouth commensals only.

\section{Comment}

We suggest that a good prospective study of pneumococcal pneumonia is needed to establish whether transmission is common, especially where contacts have a history of underlying lung disease or other predisposing factors. ${ }^{5}$ The high mortality from this condition should not be forgotten and the importance of obtaining blood cultures as well as sputum culture from patients with a clinical diagnosis of pneumonia cannot be overemphasised.

We thank Dr P Howard and Dr J D Ward for permission to report their cases, and $\mathrm{Mr} \mathrm{R}$ Howden for typing the pneumococcal isolates.

${ }^{1}$ MacLeod CM, Hodges RG, Heidelberger M, Bernhard WG. Prevention of pneumococcal pneumonia by immunisation with specific capsular polysaccharides. F Exp Med 1945;82:445-65.

${ }^{2}$ Austrian R. Prevention of pneumococcal infection by immunization with capsular polysaccharides of streptococcus pneumoniae: current status of polyvalent vaccines. F Infect Dis 1977;136, suppl:838-42.

${ }^{3}$ Austrian R, Bennett IL. Pneumococcal infections. In: Harrison's principles of internal medicine. New York: McGraw-Hill Book Co, 1974:766-72.

- Austrian R. Pneumococcal infection and pneumococcal vaccine. $N$ Engl f Med 1977;297:938-9.

-Gopal V, Bisno AL. Fulminant pneumococcal infections in "normal" asplenic hosts. Arch Intern Med 1977;137:1526-30.

(Accepted 20 April 1983)

Royal Hallamshire Hospital, Sheffield S10 2JF

P A FENTON, MB, BS, bacteriology registrar

R C SPENCER, MSC, MRCPATH, consultant microbiologist

I S SAVILL, BA, $\mathrm{MB}$, senior house officer, department of medicine

$S$ GROVER, MB, CHB, house officer

Correspondence to: Dr P A Fenton, Department of Bacteriology, Floor F, Royal Hallamshire Hospital, Sheffield S10 2JF.

\section{Relative palatability of liquid enteral feeds for general hospital patients: simple method of assessment}

Many hospital patients need oral supplements to improve their daily intake of nutrients. Successful use of such supplements requires them to be sufficiently acceptable for reasonable volumes to be consumed regularly. Although manufacturers make claims for the palatability of their products, this subject has received little scientific attention, although some studies have been conducted specifically on patients with cancer. ${ }^{1}$

\section{Subjects, methods, and results}

We undertook this study to compare the acceptability of six commercially available products widely used in hospitals in the United Kingdom and comparable in composition. The products chosen were Build Up (Carnation Foods), Clinifeed 400 (Roussel Laboratories), Complan (Farley Health Products), Ensure (Abbott Laboratories), Isocal (Mead Johnson), and Nutrauxil (Kabi Vitrum). The vanilla flavour of each product was used, Complan being flavoured with vanilla essence.

A randomised double blind taste testing technique was used. Subjects were offered in random order $10 \mathrm{ml}$ samples of each product in identical containers labelled with random double digits. They were asked to rate the palatability of each product on a five point scale ranging from "like definitely" to "dislike definitely." Between tastings the palate was cleared with water and a plain water biscuit. The study comprised 47 patients ( 24 women and 23 men, mean age 55.6 years) from general surgical wards, all eating a normal hospital diet, and 48 controls ( 24 women and 24 men, mean age 32.5 years) The table shows the results, which were ranked and analysed using the $\chi^{2}$ test. Admission to hospital appeared to influence assessment of palatability since hospital patients registered fewer overall "dislike" responses $(33 \% v$ $52 \%)$ and more "like" responses $(54 \% v 33 \%)$ than controls $(p \leqslant 0.05)$.

A reproducibility study was undertaken on a separate group of 15 patients (five women and 10 men, mean age 57.2 years) to check the reliability of the method, the patients performing the test on two occasions one week apart. The results were analysed with Spearman's rank correlation and confirmed reproducibility, particularly for three of the products-namely, Build Up, Ensure, and Isocal.

\section{Comment}

The differences between patient and control responses may be accounted for by an anxiety to please or more acceptance of unusual substances by hospital patients, although certain diseases such as cancer change taste perception..$^{1-3}$ Despite these differences Build Up was clearly the product most acceptable to patients and controls, and should, therefore, be the supplement of choice. This preference may have been due to its more natural taste as it is reconstituted with fresh milk. The cost per gram nitrogen is considerably lower than that of other products tested except Complan. A practical drawback to its use is the extra time taken in preparation. Build Up has a fairly low ratio of energy to nitrogen, which could be increased by adding an energy source such as Caloreen. As Isocal was consistently the least acceptable product we recommend that it is not used as an oral supplement despite being comparable in price and composition. As the four other products are all similar in composition and acceptability we suggest that the cheapest is used.

The method used in this study is simple to perform and, under the controlled conditions described would be a useful test for assessing other products.

1 De Wys WD, Hillenbrand Herbst S. Oral feeding in the nutritional management of the cancer patient. Cancer Res 1977;37:2429-31.

${ }^{2}$ Hall JC, Staniland JR, Giles GR. Altered taste thresholds in gastrointestinal cancer. Clin Oncol 1980;6:137-42.

3 Williams LR, Cohen MH. Altered taste thresholds in lung cancer. Am $\mathfrak{F}$ Clin Nutr 1978;31:122-5.

(Accepted 20 April 1983)

School of Health and Applied Sciences, Leeds Polytechnic, Leeds LS1 3HE

P LINDA AUTY, BSC, SRD, lecturer

MARILYN A STANDING, BTECH, senior lecturer

C HUMPHREY, MD, FRCS, lecturer

Correspondence to: Mrs P L Auty.

\section{कृ}

\section{要}

